\title{
Adsorption of chromium ions from tannery effluents onto activated carbon prepared from rice husk and potato peel by $\mathrm{H}_{3} \mathrm{PO}_{4}$ activation
}

\author{
Ephraim Vunain $^{1}$ (D) Joel Brian Njewa ${ }^{1} \cdot$ Timothy Tiwonge Biswick $^{1} \cdot$ Adewale Kabir Ipadeola $^{2}$
}

Received: 20 February 2020 / Accepted: 29 July 2021 / Published online: 16 August 2021

(c) The Author(s) 2021

\begin{abstract}
Two biomass agricultural waste materials; rice husks (RH) and potato peels (PP) were used as precursors for preparation of activated carbons by chemical activation using phosphoric acid for adsorption of hexavalent chromium $[\mathrm{Cr}(\mathrm{VI})]$ from tannery effluents. The prepared rice husk (RH-AC) and potato peel activated carbon (PP-AC) were characterized by Fourier transform infrared spectroscopy, scanning electron microscopy and X-ray diffraction. Adsorption experiments were performed by varying $\mathrm{pH}$, agitation speed, contact time, adsorbent dose and initial metal ion concentration. Freundlich, Langmuir and Temkin isotherms were used to analyze the equilibrium data obtained at different adsorption conditions. It was found that the adsorption isotherms were well fitted by the Freundlich equation and the adsorption process was found to follow pseudo-second-order rate kinetics. Adsorption results obtained show a maximum $\mathrm{Cr}(\mathrm{VI})$ uptake being attained at $\mathrm{pH}$ 2.0, with chromium removal efficiency of $99.88 \%$ and $99.52 \%$ for RH-AC and PP-AC, respectively. RH-AC and PP-AC are effective adsorbent for the removal of chromium(VI) ions from wastewater.
\end{abstract}

Keywords Rice husk $\cdot$ Potato peel $\cdot$ Activated carbon $\cdot$ Hexavalent chromium $\cdot$ Tannery effluent $\cdot$ Adsorption isotherms

\section{Introduction}

Water pollution from anthropogenic activities is a common problem nowadays. Chromium sulfate is a compound that is most commonly used in tanneries to stabilize animal hides by cross linking the collagen fibers and consequently the exhausted effluents produced by leather tanneries is rich in chromium (Taylor et al. 2014). The effluents from the tanning process contain both $\mathrm{Cr}(\mathrm{III})$ and $\mathrm{Cr}(\mathrm{VI})$ in high concentrations ranging from tens to hundreds of $\mathrm{mg} / \mathrm{L}$ (Yavuz et al. 2006). Although $\mathrm{Cr}$ (III) is only toxic to plants in very high concentrations and is less toxic, or nontoxic, to animals, the hexavalent form $(\mathrm{Cr}(\mathrm{VI}))$ has been considered more harmful to public health due to its carcinogenic, hemotoxic, and genotoxic properties (Nahid et al. 2020; Yavuz et al. 2006). Furthermore, $\mathrm{Cr}(\mathrm{VI})$ is more hazardous than $\mathrm{Cr}(\mathrm{III})$ due to its greater solubility and easy absorption and accumulation

Ephraim Vunain

evunain@cc.ac.mw

1 Department of Chemistry, University of Malawi Chancellor College, P. O Box 280, Zomba, Malawi

2 School of Chemistry, University of the Witwatersrand, Johannesburg, South Africa in human organs such as, kidneys, stomach and liver (Chen et al. 2018). Therefore, it is imperative to eliminate or reduce $\mathrm{Cr}(\mathrm{VI})$ from tannery effluents before their discharge to natural waters. Physical and chemical processes are employed in the removal of chromium and other heavy metals from aqueous media. These include ion exchange, chemical precipitation, solvent extraction, filtration, electrochemical treatment, adsorption and application of membrane technology. However, some of these processes have drawbacks including generation of toxic sludge that may lead to disposal problems, requirements for expensive equipment and monitoring system, and incomplete metal removal (Demiral et al. 2008). Adsorption with activated carbon can be an effective method when combined with appropriate regeneration steps, for removing chromium and other heavy metals from wastewater. This method is more economically viable, especially if low-cost and readily available adsorbents are used (Kilic et al. 2014; Ghaedi et al. 2014). The high adsorption capacity of activated carbon is attributed to its well-developed pore structure, and the presence of various functional groups on its surface. A number of researchers have reported on the use of activated carbon produced from low-cost and readily available materials such as agricultural and agroforestry waste materials in the removal of heavy metals including 
chromium (Awwad et al. 2010; Gueye et al. 2014; Taylor et al. 2015; Vunain et al. 2017).

In the present study, the synthesis of RH-AC and PP-AC was carried out by employing low-cost domestic agricultural wastes, i.e., rice husk and potato peel. Rice husks and potato peels are found abundantly in Malawi and often create disposal problems. Therefore, using them as precursor for preparing activated carbon will not only provide a cheap source of activated carbon but also solve solid waste disposal problems. The objective of this work is to investigate the performance of $\mathrm{RH}-\mathrm{AC}$ and $\mathrm{PP}-\mathrm{AC}$ for $\mathrm{Cr}(\mathrm{VI})$ removal from tannery wastewater at different experimental conditions. Parameters such as initial $\mathrm{pH}$, adsorbent dosage, initial concentration and agitation speed were investigated to find their effects on the adsorption of $\mathrm{Cr}(\mathrm{VI})$.

\section{Materials and methods}

\section{Sample collection}

Chromium-containing wastewater was collected from Liwonde leather tannery factory, Machinga District, Southern Region, Malawi. The wastewater was collected in $5 \mathrm{~L}$ polyethylene plastic containers (prewashed with diluted nitric acid) and immediately transported in the cooler ice bath to the laboratory and stored in a refrigerator for analysis. Conductivity, $\mathrm{pH}$, total dissolved solids, and temperature were measured onsite with Hanna's portable multi-parameter probe (Hanna HI-991301 EC/TDS/pH and Temperature Sensor).

\section{Preparation of adsorbents}

Rice husk (obtained as agricultural waste from a local rice milling plant in Zomba, Malawi) and potato peel (obtained as kitchen waste) were washed thoroughly with deionized water. The precursors were sun-dried for a day and then oven-dried at $80^{\circ} \mathrm{C}$ for $12 \mathrm{~h}$. The dried samples were then grinded using an electric blender and sieved to obtain precursors powder of particle size less than $500 \mu \mathrm{m}$. The powders were kept in air-tight containers. Activated carbons were prepared using chemical activation process according to the procedure by $\mathrm{Li}$ et al. (2015). In a typical experiment, $30 \mathrm{~g}$ of rice husk were first soaked in $200 \mathrm{~mL}$ of $3 \mathrm{Mol} \mathrm{L}^{-1}$ sodium hydroxide $(\mathrm{NaOH})$ and left in an oven at $105^{\circ} \mathrm{C}$ for $5 \mathrm{~h}$. Sodium hydroxide reacted with silica present in rice husks powder producing soluble sodium silicate $\left(\mathrm{Na}_{2} \mathrm{SiO}_{3}\right)$. Thereafter, the treated base solid residues were washed with deionized water repetitively until the $\mathrm{pH}$ of the supernatant was neutral and finally oven-dried at $110{ }^{\circ} \mathrm{C}$ for $24 \mathrm{~h}$ and used in the synthesis of activated carbon.
About $10 \mathrm{~g}$ of treated base residues and potato peel powder was impregnated with $40 \%$ orthophosphoric acid $\left(\mathrm{H}_{3} \mathrm{PO}_{4}\right)$ at 1:1.7 (w/w\%) impregnation ratio for $24 \mathrm{~h}$ at room temperature. After impregnation, the rice husk and potato peel samples were air dried at room temperature. This was then followed by the pyrolysis treatment (activation) step in which, about $100 \mathrm{~g}$ of the rice husk and potato peel were placed in pre-weighed glass crucibles and carbonized in a muffle furnace for $2.5 \mathrm{~h}$ in the absence of oxygen at a temperature of $600{ }^{\circ} \mathrm{C}$. The resulting activated carbons were ground into powder and washed with $1 \mathrm{~L}$ of deionized water to remove residual acid. Finally, the activated carbons were dried at $105{ }^{\circ} \mathrm{C}$ for $30 \mathrm{~min}$ in an oven and sieved with $106 \mu \mathrm{m}$ mesh size to obtain fine powder of activated carbons designated as $\mathrm{RH}-\mathrm{AC}$ and $\mathrm{PP}-\mathrm{AC}$ for rice husks and potato peel generated activated carbon, respectively. The powdered activated carbons were kept in air-tight containers until used.

\section{Adsorbate}

The wastewater tested in this investigation was obtained from main drain of tanning company at Liwonde, Machinga district, Malawi. The various characteristics of the tannery wastewater are shown in Table 1.

\section{Batch adsorption studies}

The batch adsorption experimental studies were conducted in $250 \mathrm{~mL}$ conical flasks at room temperature. The required mass of adsorbents was measured with electronic balance and transferred into the conical flasks. Then, $50 \mathrm{~mL}$ of the wastewater was introduced into the flask and then mounted on an orbital shaker (SSM 1) at the constant agitation speed of $280 \mathrm{rpm}$. After the desired time had elapsed the samples were centrifuged and residual chromium concentration in the supernatant was determined using Flame Atomic

Table 1 Characteristics of raw tannery wastewater from tanning company

\begin{tabular}{ll}
\hline Parameter & Effluent quality \\
\hline $\mathrm{pH}$ & 6.28 \\
Temperature & $38.6^{\circ} \mathrm{C}$ \\
Total chromium $(\mathrm{mg} / \mathrm{L})$ & $3.249 \mathrm{mg} / \mathrm{L}$ \\
Turbidity & $234.6 \mathrm{NTU}$ \\
Total dissolved substances & $1988 \mathrm{mg} / \mathrm{L}$ \\
Conductivity & $2878.32 \mu \mathrm{S} / \mathrm{cm}$ \\
Sulfite & $15.1326 \mathrm{mg} / \mathrm{L}$ \\
Calcium & $34.132 \mathrm{mg} / \mathrm{L}$ \\
Magnesium & $28.4325 \mathrm{mg} / \mathrm{L}$ \\
Nitrate & $69.8474 \mathrm{mg} / \mathrm{L}$ \\
sodium & $1619.8 \mathrm{mg} / \mathrm{L}$ \\
\hline
\end{tabular}


Absorption Spectrometry (Agilent Technologies 200 Series) at $(357.9 \mathrm{~nm})$ wavelength. Several working parameters such as agitation speed, initial concentration, contact time, solution $\mathrm{pH}$, and adsorbent dose were studied. These operating parameters were kept constant except the one being studied. The experiments were run in duplicate. The reaction parameters were optimized using laboratory prepared $\mathrm{Cr}(\mathrm{VI})$ solutions. Once this was achieved, experiments were then undertaken on the real wastewater sample from Liwonde tannery factory at optimized conditions.

The adsorption capacity at equilibrium $q_{\mathrm{e}}(\mathrm{mg} / \mathrm{g})$ and percentage removal for chromium ions was calculated by the given equations, respectively.

$q_{\mathrm{e}}=\frac{\left(C_{\mathrm{o}}-C_{\mathrm{e}}\right) V}{m}$

$\operatorname{Re} \%=\frac{\left(C_{\mathrm{o}}-C_{\mathrm{e}}\right) \times 100}{C_{\mathrm{o}}}$

where $C_{0}$ is the initial chromium ions concentration $(\mathrm{mg} / \mathrm{L})$, $C_{\mathrm{e}}$ is the concentrations of chromium ions at the equilibrium time $(\mathrm{mg} / \mathrm{L}), m$ is the mass of adsorbent $(\mathrm{g})$, and $V$ is the volume of the solution $(\mathrm{L})$.

\section{Desorption studies}

Desorption and regeneration studies were carried out to evaluate the reusability of the agro-based adsorbents. A simple method that uses hot water and sodium hydroxide $(0.1 \mathrm{M}$ $\mathrm{NaOH}$ ) was selected. The wastewater with an initial concentration of $10 \mathrm{mg} / \mathrm{L}$ prepared through dilution of $\mathrm{Cr}$ standard solution $(1000 \mathrm{ppm})$ was used in the desorption studies. The already used ACs $(1 \mathrm{~g})$ were introduced into $100 \mathrm{~mL}$ of distilled water was heated up to $80{ }^{\circ} \mathrm{C}$ for approximately 30 min to eliminate the physically adsorbed chromium ions. Then, the samples were several times flushed with $100 \mathrm{~mL}$ of $0.1 \mathrm{M} \mathrm{NaOH}$ to remove the remaining chromium ions on the surface of the adsorbents. The sodium hydroxide used altered the surface chemistry of the adsorbents as it results in deprotonation. Thereafter, the adsorbents were washed with distilled water several times until the $\mathrm{pH}$ of the supernatant was neutral, and the above process was repeated two times.

\section{Results and discussions}

\section{Characterization of activated carbon}

\section{Fourier transform infrared spectroscopy FT-IR}

The infrared spectroscopy (FT-IR) spectra for the prepared activated carbons are shown in Fig. 1. In both spectra, the weak peaks appearing at around, $3854 \mathrm{~cm}^{-1}$, $3743 \mathrm{~cm}^{-1}$, and $3608 \mathrm{~cm}^{-1}$ are associated with bond stretching vibrations of alcohols $(\mathrm{O}-\mathrm{H})$. The absorption peaks at $3386 \mathrm{~cm}^{-1}$ and $1548 \mathrm{~cm}^{-1}$ wavenumbers are associated with amines $\left(\mathrm{NH}_{2}\right)$ and nitrogen-oxy compounds (N-O) symmetric stretching vibrations, respectively (Guo et al. 2015). The peaks observed at 1673 and $1250 \mathrm{~cm}^{-1}$ for RH-AC spectrum are associated with $\mathrm{C}=\mathrm{C}$ and $\mathrm{Si}-\mathrm{CH}_{3}$ ) stretching, respectively (Barot and Bagla 2012). The peaks observed at 1281 and $961 \mathrm{~cm}^{-1}$ for PP-AC are related to phosphorous species due to activating agent $\left(\mathrm{H}_{3} \mathrm{PO}_{4}\right)$ (Vunain et al. 2017). The peaks observed at $1057 \mathrm{~cm}^{-1}$ and $1116 \mathrm{~cm}^{-1}$ in both activated carbons, are associated with $(\mathrm{OH})$, carboxylic acids (C-OH) (Hashemian et al. 2015) and due
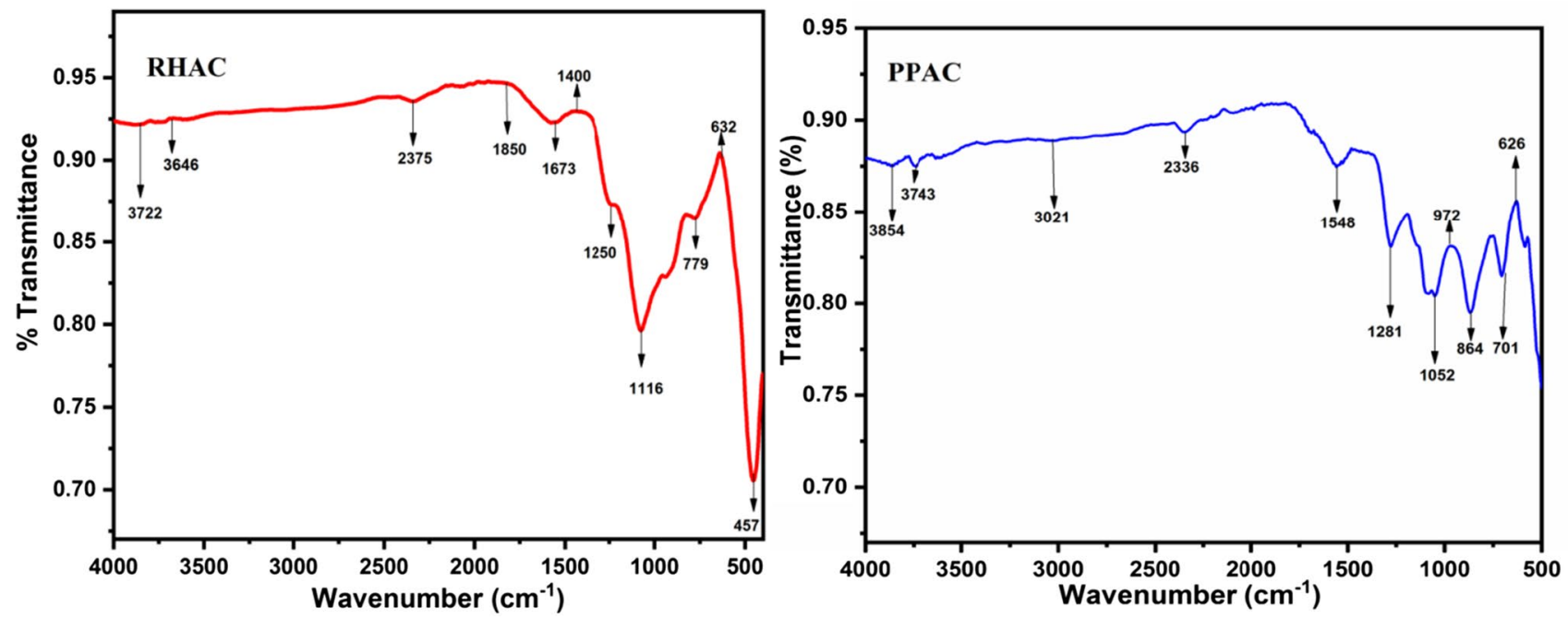

Fig. 1 FT-IR spectra of rice husk (RH-AC) and potato peel (PP-AC) prepared at $600{ }^{\circ} \mathrm{C}$ 
to $(\mathrm{S}=\mathrm{O})$ bond, respectively. The peaks at wavenumbers 1400,779 and $632 \mathrm{~cm}^{-1}$, are due to stretching of $(\mathrm{C}-\mathrm{C})$ alkyl bond vibrations $(\mathrm{C}-\mathrm{H})$ and aryl halides stretching (C-Br) correspondingly (Anirudhan and Sreekumari 2011). The presence of peaks at, 2180, 2084, 1850 and $1169 \mathrm{~cm}^{-1}$ correspond to bond stretching vibrations of alkynes $(\mathrm{C} \equiv \mathrm{C})$, carboxylic acids $(\mathrm{C}=\mathrm{O})$ and sulfur-oxy compounds $\left(\mathrm{SO}_{3} \mathrm{H}\right)$. Furthermore, the peaks at 2375 and $3021 \mathrm{~cm}^{-1}$ wavenumbers are due to $\mathrm{CO}_{2}$ and $(\mathrm{C}-\mathrm{H})$ bond stretching. The activated carbons prepared demonstrated good surface chemistry as they contain multiple functional groups responsible for adsorbing properties such as amines, alcohols among others.

\section{Scanning electron microscopy (SEM)}

Scanning electron microscopy (SEM) technique was used to investigate the surface morphology of the activated carbon derived from rice husk and activated carbon derived from potato peel prepared at $600{ }^{\circ} \mathrm{C}$ (Fig. 2). The two micrographs showed that the carbon presented a porous structure with some macroporous pores on the surface. It is clear that the activated carbon samples have considerably number of pores and there is a good possibility for the chromium ion molecules to be trapped and adsorbed in these pores. On the basis of these facts, it can be concluded that the prepared activated carbons from rice husk and potato peel present an adequate morphology for chromium adsorption from tannery wastewater.

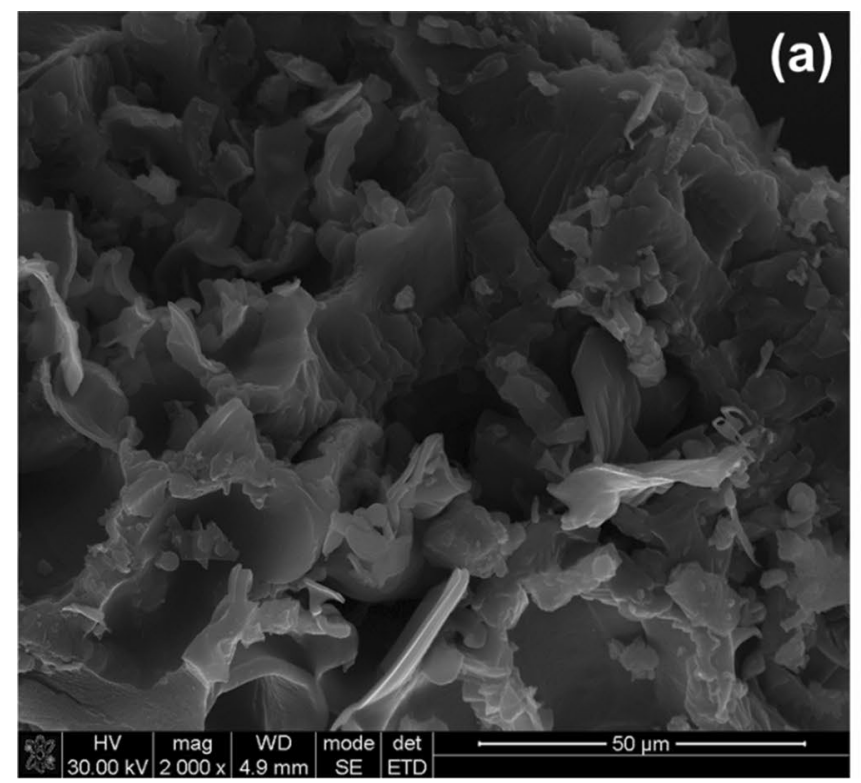

\section{X-ray diffraction patterns (XRD)}

Figure 3 shows the XRD patterns of RH-AC and PP-AC. The defined sharp peaks observed at $2 \theta=23.30,42.30$ for $\mathrm{RH}-\mathrm{AC}$, and at $2 \theta=23.0,41.60$, for PP-AC are associated with the presence of carbon and graphite, corresponding to values of $\mathrm{d}_{002}$ and $\mathrm{d}_{101}$ of graphitic carbon while the peaks appearing in the lower range $2 \theta=13.80-20.70$ are associated with the presence of residual cellulose crystallites (Qin et al. 2014) These are linked with residual cellulose crystallites and observed in some other patterns of AC prepared from agricultural wastes. This indicates that the attack of $\mathrm{H}_{3} \mathrm{PO}_{4}$ on lignocellulosic materials does not completely destroy the primary stages of constituent cellulose crystallites (Girgis et al. 2007). However, the peaks appearing in range $2 \theta=25-39.10$ are connected with phosphorous compounds contained in the activated carbon sample. During the carbonization of lignocellulosic materials, the phosphoric acid $\mathrm{H}_{3} \mathrm{PO}_{4}$ is changed into different polyphosphoric acids and phosphoric acid and its byproducts formed phosphate and polyphosphate bridges that connected the biopolymer fragments (Qin et al. 2014). These results showed that the activated carbons prepared were amorphous with a small crystalline domain and that due to the reactions between phosphoric acid and cellulose, part of the crystalline structure was destroyed. However, activated carbon prepared from potato peels contained some phosphorous impurities emerging from the activating agent. The presence of phosphorus impurities can be confirmed by the appearance of several peaks on the XRD spectrum. Other researchers have reported similar XRD patterns on activated carbon prepared

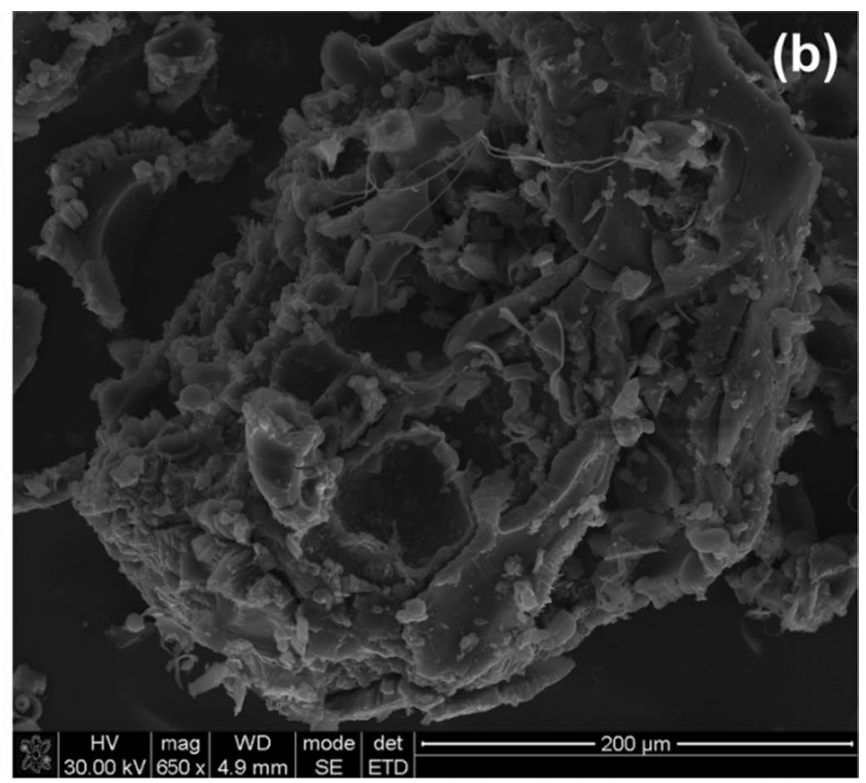

Fig. 2 Scanning electron microscopy (SEM) micrographs for a RH-AC and b PP-AC prepared at $600{ }^{\circ} \mathrm{C}$ 


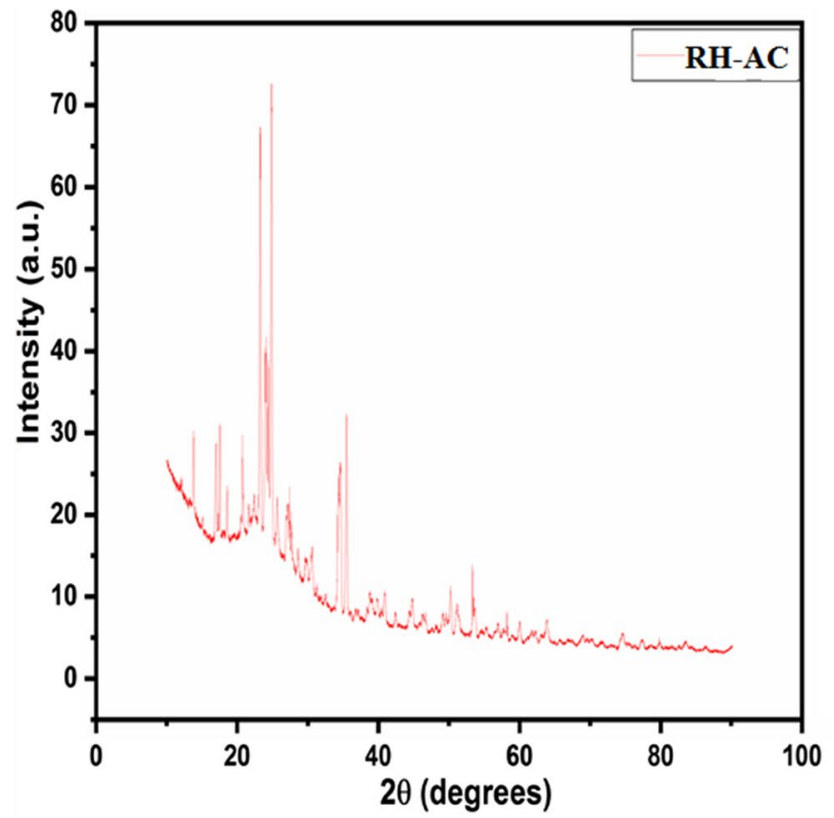

Fig. 3 XRD patterns of $\mathrm{RH}-\mathrm{AC}$ and $\mathrm{PP}-\mathrm{AC}$ prepared at $600{ }^{\circ} \mathrm{C}$

from agricultural residues (Islam et al. 2016; Sugashini et al. 2015).

\section{Absorption and desorption studies of the activated carbon}

\section{Effect of $\mathrm{pH}$}

The effect of solution $\mathrm{pH}$ on the removal of chromium ions was performed over a $\mathrm{pH}$ range of 1.4-12.0 while maintaining the other parameters constant as follows: $300 \mathrm{mg}$ adsorbent dosage, initial $\mathrm{Cr}$ concentration of $3.249 \mathrm{mg} / \mathrm{L}$, agitation speed of $280 \mathrm{rpm}$, and contact time of $180 \mathrm{~min}$. The desired solution $\mathrm{pH}$ was achieved by drop-wise addition of either $0.1 \mathrm{MHCl}$ or $0.1 \mathrm{M} \mathrm{NaOH}$. The results presented in Fig. 4 show that the percentage adsorption is higher at acidic medium (1.4-6.8), reaching a maximum of about $99.88 \%$ and $98.52 \%$, for $\mathrm{RH}-\mathrm{AC}$ and $\mathrm{PP}-\mathrm{AC}$, respectively. However, the level of $\mathrm{Cr}$ ions adsorption reduced gradually as $\mathrm{pH}$ was increased. The adsorption ability of RH-AC for $\mathrm{Cr}$ at $\mathrm{pH} 2$ was $3.245 \mathrm{mg} / \mathrm{L}$, which decreased to $0.401 \mathrm{mg} / \mathrm{L}$ as $\mathrm{pH}$ was increased to 12.0 . Likewise, for PP-AC the highest $\mathrm{Cr}$ ions adsorption capacity was $3.201 \mathrm{mg} / \mathrm{L}$ realized at $\mathrm{pH} 2.0$, which tremendously reduced to $0.083 \mathrm{mg} / \mathrm{L}$ with an increase of $\mathrm{pH}$ to 12.0 as well. These results show that the maximum $\mathrm{Cr}$ ions removal by $\mathrm{RH}-\mathrm{AC}$ and $\mathrm{PP}-\mathrm{AC}$ samples was higher in acidic medium whereas the in alkaline condition, adsorption of $\mathrm{Cr}(\mathrm{VI})$ was lower for the two adsorbents. $\mathrm{Cr}(\mathrm{VI})$

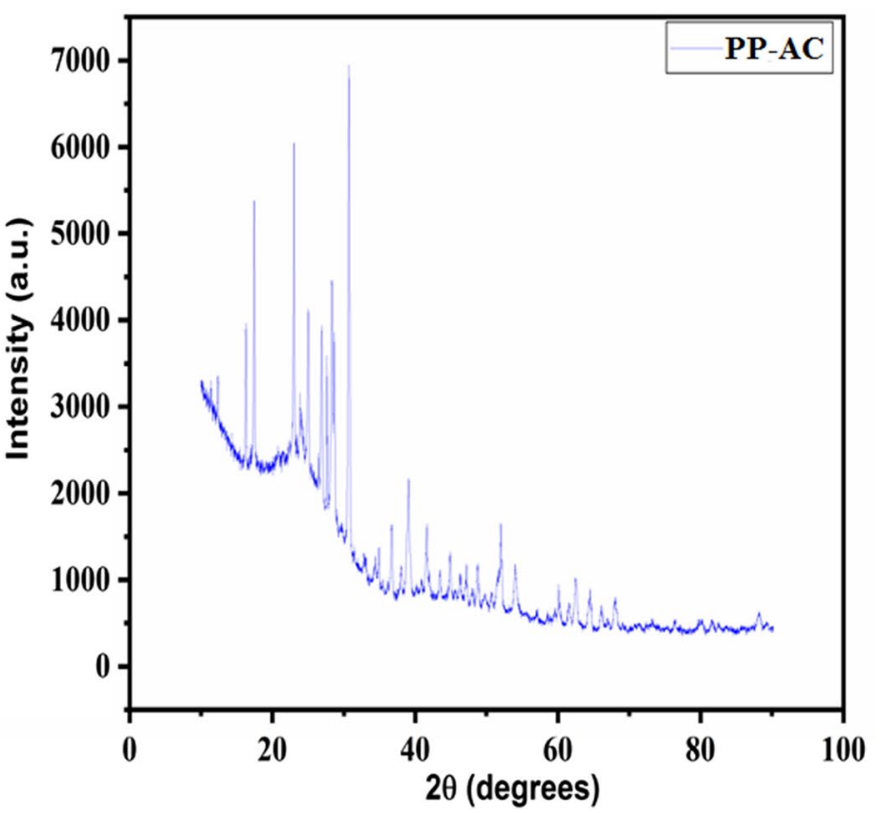

exists in different stable states such as chromate $\left(\mathrm{CrO}_{4}{ }^{2-}\right)$ acid, chromate $\left(\mathrm{HCrO}_{4}^{-}\right)$, dichromate $\left(\mathrm{Cr}_{2} \mathrm{O}_{7}{ }^{2-}\right)$ and $\mathrm{HCr}_{2} \mathrm{O}_{7}{ }^{-}$ions in aqueous solution and the stability of these species is dependent on the $\mathrm{pH}$ of the system and among these forms, $\mathrm{HCrO}_{4}{ }^{-}$is the more dominant in an acidic medium (Mullick et al. 2017; Rahman et al. 2017). The $\mathrm{pH}$ dependence of chromium ions uptake can further be elucidated by chromium species speciation and the adsorbent surface charge at point of zero charge. At $\mathrm{pH}$ below $\mathrm{pH}_{\mathrm{pzc}}(<6.8)$, the RH-AC and PP-AC surfaces become protonated promoting a strong attraction between the anion $\left(\mathrm{HCrO}_{4}^{-}\right)$and the adsorbent surface oxygen functional groups such as, carboxyl $(\mathrm{C}-\mathrm{O})$, carbonyl $(\mathrm{C}=\mathrm{O})$, and hydroxyl $(\mathrm{O}-\mathrm{H})$ as shown in Eqs. 1 and 2. But, at $\mathrm{pH}$ above $\mathrm{pH}_{\mathrm{pzc}}(>6.8) \mathrm{OH}$ groups are attached to the surfaces of the adsorbents which hinders attraction between the chromium-containing anions and the $\mathrm{RH}-\mathrm{AC}$ and $\mathrm{PP}-\mathrm{AC}$ surfaces, lowering the adsorbate removal (Yusuff 2019).

$\left[\mathrm{RHAC}-\mathrm{OH}_{2}\right]^{+}+\mathrm{HCrO}_{4}^{-} \rightarrow \mathrm{RHACCrO}_{4}+\mathrm{H}_{2} \mathrm{O} \quad \mathrm{pH}<\mathrm{pH}_{\mathrm{pzc}}$

$\left[\mathrm{PPAC}-\mathrm{OH}_{2}\right]^{+}+\mathrm{HCrO}_{4}^{-} \rightarrow \mathrm{PPACCrO}_{4}+\mathrm{H}_{2} \mathrm{O} \quad \mathrm{pH}<\mathrm{pH}_{\mathrm{pzc}}$

where $\left[\mathrm{RHAC}-\mathrm{OH}_{2}\right]^{+}$and $\left[\mathrm{PPAC}-\mathrm{OH}_{2}\right]^{+}$represent the protonated functional groups on the surface of the adsorbent (Lataye et al. 2016). Similar observations have been reported by other investigators who worked on adsorption of $\mathrm{Cr}$ ions from wastewater with activated carbons (Berihun 2016; Rai 2016). 
Fig. 4 Effect of solution $\mathrm{pH}$ on $\mathrm{Cr}$ (VI) adsorption by $\mathrm{RH}-\mathrm{AC}$ and $\mathrm{PP}-\mathrm{AC}$ prepared at $600{ }^{\circ} \mathrm{C}(300 \mathrm{mg}$ adsorbent dosage, initial $\mathrm{Cr}$ concentration of $3.249 \mathrm{mg} / \mathrm{L}$, agitation speed of $280 \mathrm{rpm}$, contact time of $180 \mathrm{~min}$ and temperature of $\left.25^{\circ} \mathrm{C}\right)$

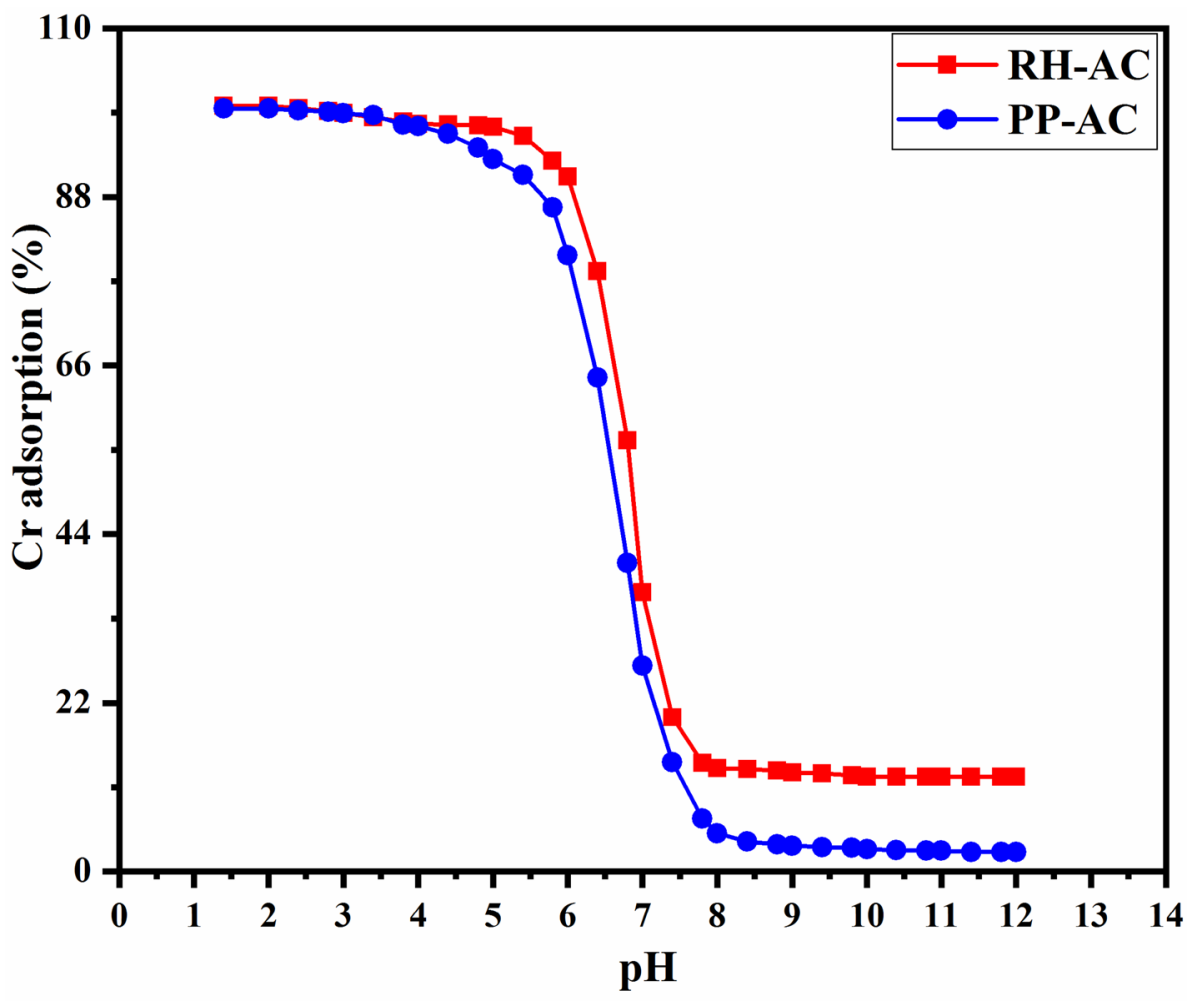

\section{Effect of Initial metal ion concentration}

The influence of initial concentration on chromium ions on adsorption was performed with different initial concentrations ranging from 10 to $200 \mathrm{mg} / \mathrm{L}$, agitation speed of $280 \mathrm{rpm}$, at optimized pH of 2, adsorbent dose of $300 \mathrm{mg}$, and contact time of 180 min. Different initial concentrations of $\mathrm{Cr}$ solutions were prepared by proper dilution of $1000 \mathrm{mg} / \mathrm{L} \mathrm{Cr}$ standard solution with distilled water. The results, presented in Fig. 5, show that with an increase in adsorbate concentration from 10 to $200 \mathrm{mg} / \mathrm{L}$, the equilibrium amount of $\mathrm{Cr}$ ions removed increased from 1.58 to
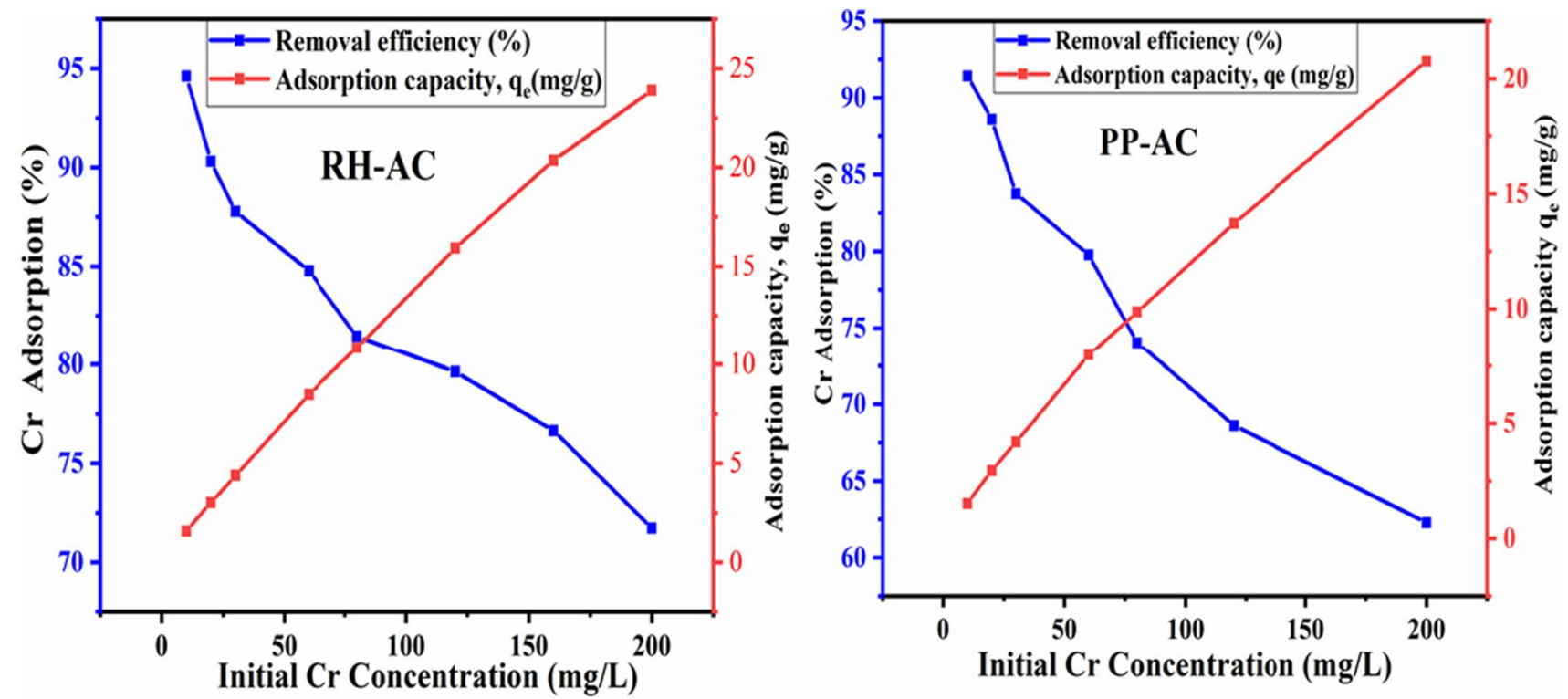

Fig. 5 Effect of initial $\mathrm{Cr}$ (VI) concentration on metal uptake (mg/L) by RH-AC and PP-AC prepared at $600{ }^{\circ} \mathrm{C}$. (300 mg of adsorbent dosage, agitation speed of $280 \mathrm{rpm}$, contact time of $180 \mathrm{~min}$ and room temperature of $25^{\circ} \mathrm{C}$ ) 
$23.91 \mathrm{mg} / \mathrm{g}$ and 1.52 to $20.76 \mathrm{mg} / \mathrm{g}$ and adsorption efficiency reduced from 94.61 to $71.72 \%$ and 91.42 to $62.28 \%$ for RH-AC and PP-AC, respectively. It has been established that as the initial concentration of $\mathrm{Cr}$ ions solution was increased the removal efficiency decreased and the amount of chromium ions adsorbed per unit mass of the adsorbents increased. The increase in chromium ion adsorbed by $\mathrm{RH}-\mathrm{AC}$ and $\mathrm{PP}-\mathrm{AC}$ as $\mathrm{Cr}$ ion concentrations increase is associated with the greater presence of $\mathrm{Cr}$ ion concentration in the solution for adsorption. Furthermore, at greater initial $\mathrm{Cr}$ ion concentrations, the driving force was increased to overcome all the mass transfer resistances of metal ions between the aqueous and solid phases that increased the rate of collisions between $\mathrm{Cr}$ ions and adsorbents (Rahman et al. 2017). At lower initial $\mathrm{Cr}$ ion concentration, the rate of adsorption occurred at reduced pace but increasing the concentration resulted in the competition of binding sites on the adsorbents by chromium ions thereby increasing adsorption capacity (Dula et al. 2014). The reduction in percentage removal might be due to the fact that at higher concentration more $\mathrm{Cr}$ ions remain in the solution unadsorbed due to saturation of binding sites. This occurs due to an increase in a number of ions competing for existing binding sites in the adsorbents (Murugesan et al. 2012).

\section{Effect of adsorbent dosage}

The effect of adsorbent dosage on the adsorption of $\mathrm{Cr}(\mathrm{VI})$ ions was studied using different adsorbent dosages in the range of 50-500 mg (Fig. 6). The operating parameters including, wastewater with initial concentration of $3.249 \mathrm{mg} / \mathrm{L}$, at optimized $\mathrm{pH}$, constant agitation speed of $280 \mathrm{rpm}$ at a fixed duration of 240 min were adopted. The results indicate that the increase in an adsorbent dose for all activated carbons understudy facilitated an increase in the removal rate of chromium ions from the wastewater until equilibrium was achieved. The increase in adsorbent doses increases the adsorbent to adsorbate ratio which results in increase in the effective surface area and the active sites available on the surface of the adsorbents onto which chromium ions are accommodated (Devi and Manonmani 2015). The adsorbent dose of $300 \mathrm{mg}$ removed a maximum of, $2.918 \mathrm{mg} / \mathrm{L}$ and $2.5385 \mathrm{mg} / \mathrm{L}$ chromium ions for $\mathrm{RH}-\mathrm{AC}$ and PP-AC, respectively. Thereafter, no further changes in chromium ions removal with an increase in adsorbent dose was observed as equilibrium was attained. This indicates that highest removal of $\mathrm{Cr}$ ions was achieved with this dose likely due to the greater presence of exchangeable binding sites at higher concentration of adsorbent (Murugesan et al. 2012). A similar trend of results on chromium ions adsorption by activated carbon was also reported by other investigators (Bishnoi et al. 2004; Mohanty et al. 2014).

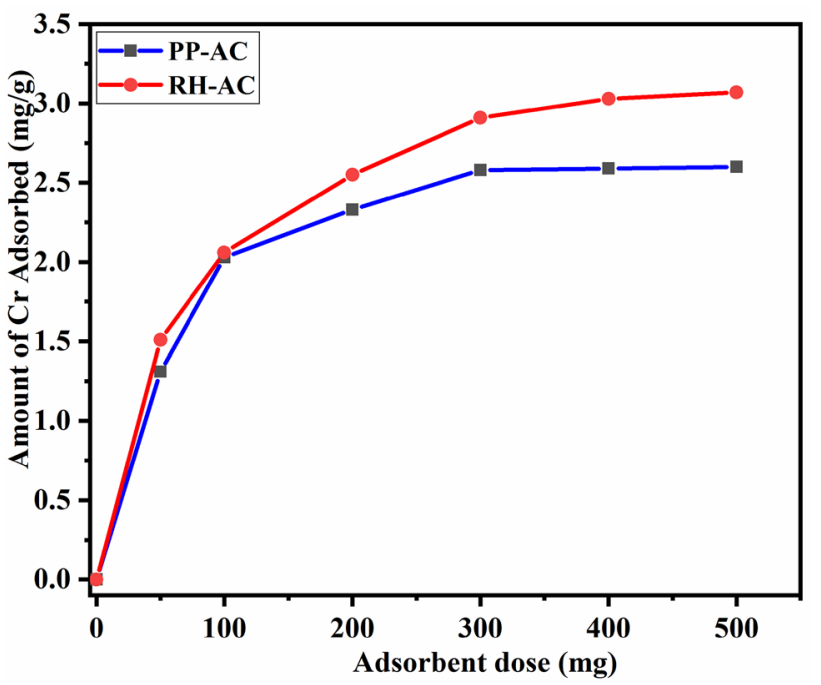

Fig. 6 Effect of adsorbent dose on $\mathrm{Cr}(\mathrm{VI})$ uptake by RH-AC and PPAC prepared at $600{ }^{\circ} \mathrm{C}(300 \mathrm{mg}$ adsorbent dosage, agitation speed of $280 \mathrm{rpm}$, contact time of $180 \mathrm{~min}$ and temperature of $25^{\circ} \mathrm{C}$ )

\section{Effect of contact time}

Contact time is considered as a significant parameter for rapid adsorption and successful practical application of adsorbents. The effect of contact time on adsorption of chromium ions onto $\mathrm{RH}-\mathrm{AC}$ and $\mathrm{PP}-\mathrm{AC}$ were studied from 10 to $360 \mathrm{~min}$ of contact time. An adsorbent mass of $300 \mathrm{mg}$ was measured and introduced into $250 \mathrm{~mL}$ conical flasks containing $50 \mathrm{~mL}$ of chromium wastewater at optimized $\mathrm{pH}$. The flasks were sealed and mounted on an orbital shaker and agitated at a speed of $280 \mathrm{rpm}$ for a chosen time. The results illustrated in Fig. 7 show that the rate of chromium ions removal by $\mathrm{RH}-\mathrm{AC}$ and $\mathrm{PP}-\mathrm{AC}$ increased with the increase in contact time until equilibrium was reached. Increasing the contact time from 10 to 360 min resulted in a maximum adsorption efficiency of $\mathrm{Cr}(\mathrm{VI})$ of $3.21 \mathrm{mg} / \mathrm{L}$ and $2.84 \mathrm{mg} / \mathrm{L}$ at $120 \mathrm{~min}$ and $240 \mathrm{~min}$ for RH-AC and PP-AC, respectively. The rapid increase in chromium ions adsorption as contact time increases could be associated with the presence of the vacant sites on the surface adsorbents until achieving equilibrium (Santhosh and Dhandapani 2013). As, contact time increases further, the decrease in chromium ion removal was observed in $\mathrm{PP}-\mathrm{AC}$, indicating saturation of adsorption sites. A similar observation was reported by Siboni et al. in the removal of hexavalent chromium from aqueous solution (Siboni et al. 2011).

\section{Effect of agitation speed}

To study the effect of agitation speed on the removal of chromium ions using activated carbons, $300 \mathrm{mg}$ of the adsorbents were measured and then introduced into a $250 \mathrm{~mL}$ conical

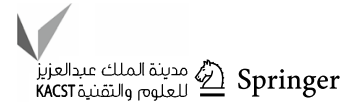




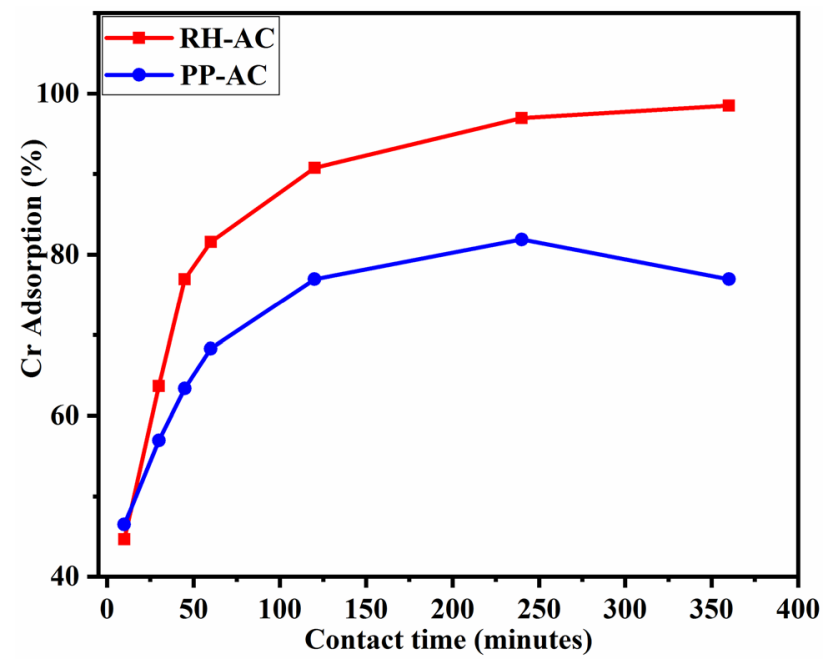

Fig. 7 Effect of contact time on $\mathrm{Cr}(\mathrm{VI})$ uptake by $\mathrm{RH}-\mathrm{AC}$ and PPAC prepared at $600{ }^{\circ} \mathrm{C}(300 \mathrm{mg}$ adsorbent dosage, agitation speed of $280 \mathrm{rpm}$, and temperature of $25^{\circ} \mathrm{C}$ )

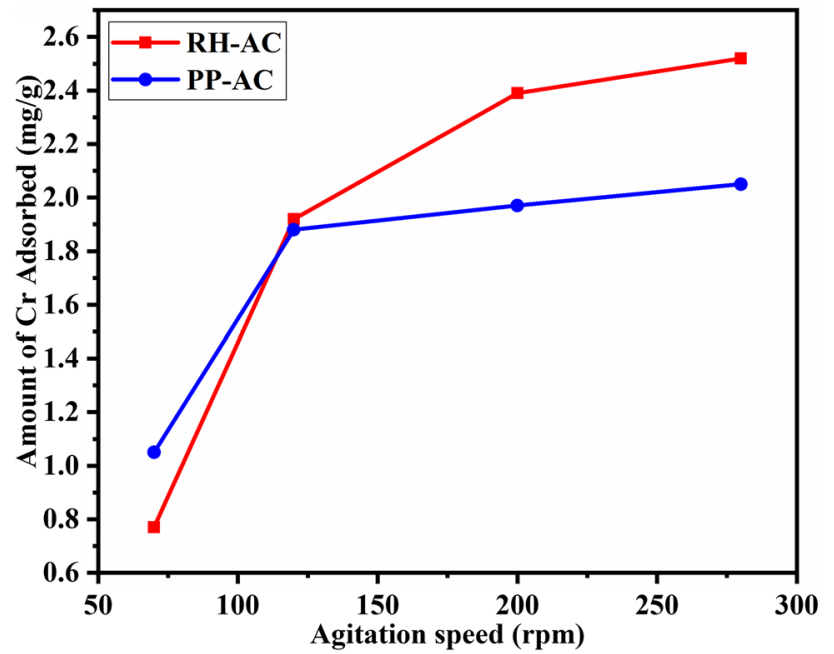

Fig. 8 Effect of agitation speed on $\mathrm{Cr}(\mathrm{VI})$ uptake by $\mathrm{RH}-\mathrm{AC}$ and PPAC prepared at $600{ }^{\circ} \mathrm{C}(300 \mathrm{mg}$ adsorbent dosage, agitation speed of $280 \mathrm{rpm}$, contact time of $180 \mathrm{~min}$ and temperature of $25^{\circ} \mathrm{C}$ )

flask containing $50 \mathrm{~mL}$ of chromium wastewater with an initial concentration of $3.249 \mathrm{mg} / \mathrm{L}$ and at optimized $\mathrm{pH}$. Thereafter, the samples were agitated at a different speed ranging (80, 120, 200 and 280) rpm for $240 \mathrm{~min}$ (Fig. 8). The results have demonstrated that an increase in agitation speed results into a high rate of chromium ions removal by $\mathrm{RH}-\mathrm{AC}$ and $\mathrm{PP}-\mathrm{AC}$. The increase in the agitation speed from 70 to $280 \mathrm{rpm}$ resulted in the high rate removal of chromium ions from 0.77 to $2.52 \mathrm{mg} / \mathrm{L}$ (28.87-77.56\%) and 1.05 to $2.06 \mathrm{mg} / \mathrm{L}$ (32.35-63.28\%) for RH-AC and PP-AC, respectively. The rapid removal efficiency at greater speeds could be attributed to the provision of good contact between adsorbents and adsorbate ions (Barot and Bagla 2012). Furthermore, increasing the shaking speed, the diffusion rate of $\mathrm{Cr}$ ions from the bulk liquid to the liquid boundary layer surrounding sorbent particles become higher due to an enhancement of turbulence and the reduction of the thickness of the liquid boundary layer (Onindo and Muthakia 2012). The agitation speed of $280 \mathrm{rpm}$ was chosen and used in the entire study as it gave high values of chromium ions removal for all adsorbents.

\section{Adsorption isotherms}

Adsorption isotherms are mathematical models used to indicate the relationship between the amount of the material adsorbed and concentration of the liquid at constant temperature (Kaushal and Singh 2017). The results of adsorption isotherms are generally calculated as a plot of the concentration of chemical substance adsorbed $(\mathrm{mg} / \mathrm{g}$ ) versus the residual concentration $(\mathrm{mg} / \mathrm{L})$. Isotherms studies are very significant in the interpretation of the adsorption process sufficiently. They indicate retention mechanisms of the solution component and solid-phase at equilibrium as well as the surface properties and affinity of the adsorbent providing an insight into how best adsorption system can be improved (Almohammadi and Mirzaei 2016). In this study three isotherms namely: Freundlich, Langmuir and Temkin, were used to validate the adsorption data.

\section{Langmuir isotherm}

The Langmuir isotherm equation is based on the assumption that adsorption happens at specific homogeneous sites in which the adsorption of every adsorbate molecules on the surface has similar sorption activation energy (Mandal 2013). The linearized form of this isotherm model can be represented as follows:

$\frac{C_{\mathrm{e}}}{q_{\mathrm{e}}}=\frac{1}{K_{\mathrm{L}} q_{\mathrm{m}}}+\frac{C_{\mathrm{e}}}{q_{\mathrm{m}}}$

where $q_{\mathrm{e}}(\mathrm{mg} / \mathrm{g})$ and $C_{\mathrm{e}}(\mathrm{mg} / \mathrm{g})$ are the amount of adsorbed adsorbate per unit weight of adsorbent and remaining adsorbate concentration in solution at equilibrium, respectively. $K_{\mathrm{L}}(\mathrm{L} / \mathrm{mg})$ and $q_{\mathrm{m}}$ are Langmuir constant and theoretical monolayer saturation capacity correspondingly. To ascertain if the adsorption was favorable or unfavorable, the dimensionless constant named separation factor $\left(R_{\mathrm{L}}\right)$ also termed as equilibrium parameter usually defined by the given relationship below was used:

$R_{\mathrm{L}}=\frac{1}{1+K_{\mathrm{L}} C_{\mathrm{o}}}$ 
where $C_{\mathrm{O}}(\mathrm{mg} / \mathrm{L})$ is the initial adsorbate concentration. The value of $R_{\mathrm{L}}$ shows the shape of the isotherms to be either unfavorable when $R_{\mathrm{L}}>1$, linear when $R_{\mathrm{L}}=1$, favorable when $0<R_{\mathrm{L}}<1$ or irreversible when $R_{\mathrm{L}}=0$ (Kumar et al. 2014; Madala et al.2013; Naiya et al. 2009). The constant parameters $K_{\mathrm{L}}$ and $q_{\mathrm{m}}$ were calculated from the slope and intercept of the linear plot of $C_{\mathrm{e}} / q_{\mathrm{e}}$ versus $C_{\mathrm{e}}$ of this isotherm model at $25^{\circ} \mathrm{C}$, which are listed in the (Table 2). From the linear form of Langmuir model (Fig. 9a, b), the $\left(R^{2}\right)$ values of 0.997 and 0.921 for RH-AC and PP-AC, respectively. The regression coefficients obtained indicate successful fitting of the experimental data especially for adsorption of chromium ions by RH-AC, followed by PP-AC. The results suggest that the adsorption of chromium ions on the surface of the $\mathrm{RH}-\mathrm{AC}$ was a monolayer occurring at specific homogeneous sites due to interaction with the functional groups (Yang et al. 2014). The separation factor $\left(R_{\mathrm{L}}\right)$ values calculated are 0.080 and 0.247 for RH-AC and PP-AC, respectively. The above values obtained are in the required range of between 0 and 1 , as desired for favorable adsorption (Chakravarty et al. 2010; Demiral et al. 2008; Vunain and Biswick 2018). The results also show the practicability of adsorption of chromium ions from aqueous solution with prepared adsorbents and also suggest the distribution of the active sites on the surfaces of the RH-AC and PP-AC adsorbents (Devi and Manonmani 2015).

Table 2 Isotherm constant for the adsorption of chromium ions by $\mathrm{RH}-\mathrm{AC}$ and $\mathrm{PP}-\mathrm{AC}$

\begin{tabular}{|c|c|c|c|c|c|c|c|c|c|}
\hline & \multicolumn{3}{|c|}{ Langmuir } & \multicolumn{3}{|l|}{ Freundlich } & \multicolumn{3}{|l|}{ Temkin } \\
\hline & $\mathrm{q}_{\mathrm{m}}$ & $\mathrm{b}$ & $\mathrm{R}^{2}$ & $\mathrm{k}_{\mathrm{f}}$ & $\mathrm{n}$ & $\mathrm{R}^{2}$ & $\mathrm{~B}_{\mathrm{T}}$ & $\mathrm{A}_{\mathrm{T}}$ & $\mathrm{R}^{2}$ \\
\hline $\mathrm{RH}-\mathrm{AC}$ & 3.55 & $6.2 \times 10^{-4}$ & 0.997 & $4.6 \times 10^{-4}$ & 3.096 & 0.973 & $5.44 \times 10^{3}$ & 1.001 & 0.973 \\
\hline $\mathrm{PP}-\mathrm{AC}$ & 0.94 & $8.3 \times 10^{-4}$ & 0.920 & $3.6 \times 10^{-4}$ & 1.888 & 0.989 & $3.12 \times 10^{4}$ & 1.054 & 0.923 \\
\hline
\end{tabular}
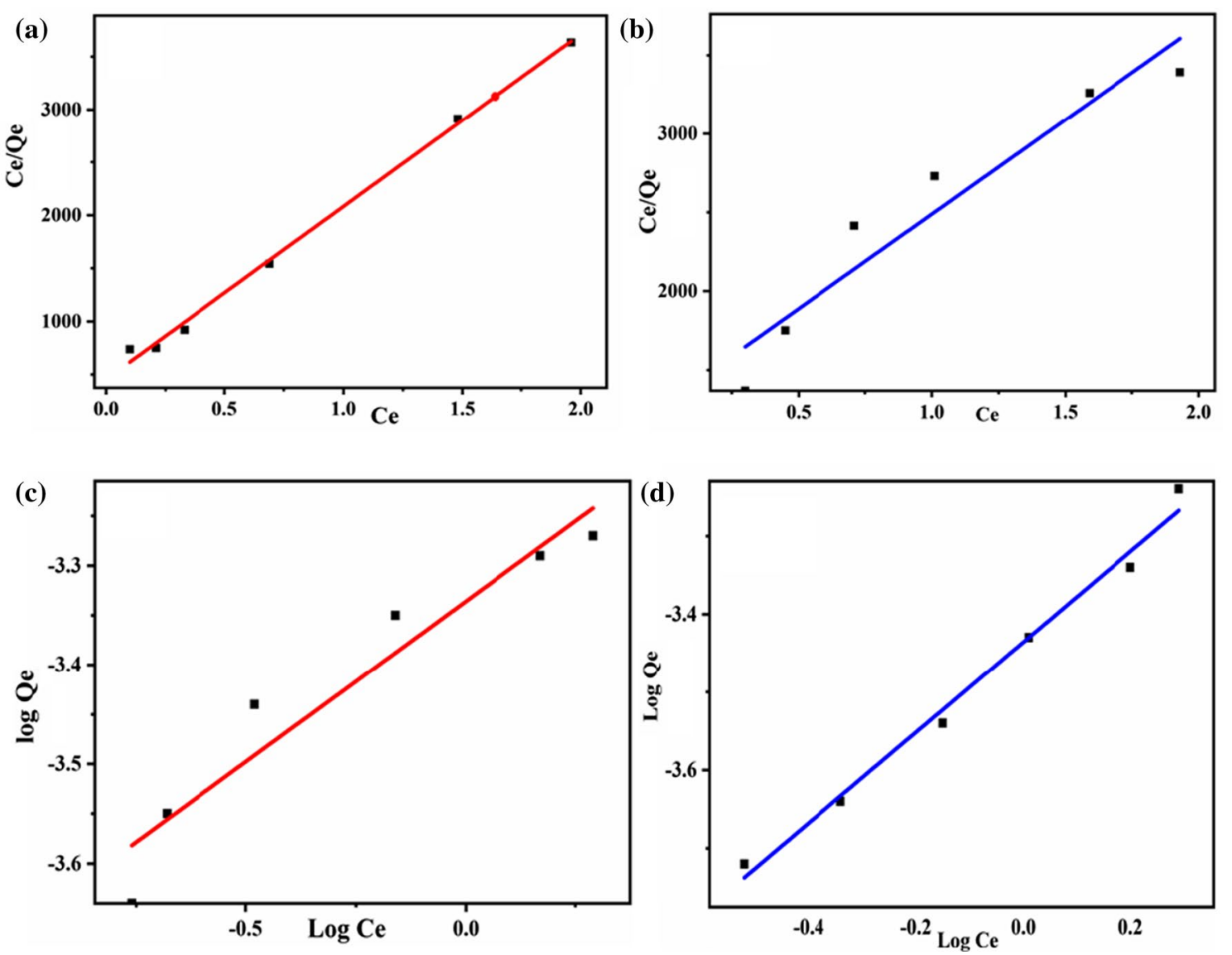

Fig. 9 Langmuir plot for $\mathrm{Cr}$ adsorption on RH-AC (a); Langmuir plot for $\mathrm{Cr}$ adsorption on $\mathrm{PP}-\mathrm{AC}$ (b) and Freundlich plot for Cr adsorption on $\mathrm{RH}-\mathrm{AC}$ (c); Freundlich plot for Cr adsorption on PP-AC (d) 


\section{Freundlich isotherm}

This model is empirical in nature and founded on the assumptions that adsorption occurs on the heterogeneous surface and an exponential distribution of active sites (Hameed et al. 2008). The heterogeneous sorption linear model of Freundlich isotherm is expressed by the following relationship:

$\log q_{\mathrm{e}}=\log K_{\mathrm{f}}+\frac{1}{n} \log C_{\mathrm{e}}$

where $q_{\mathrm{e}}$, is the adsorption capacity $(\mathrm{mg} / \mathrm{g}), C_{\mathrm{e}}$ is the equilibrium concentration of the adsorbate solution $(\mathrm{mg} / \mathrm{L}), K_{\mathrm{F}}$ and $n$ are Freundlich constants which represents adsorption capacity and adsorption intensity, respectively. Generally, the greater the value of $K_{\mathrm{F}}$, indicates the more heterogeneity and the values of $n$ between 1 and 10 (i.e., $1 / n$ less than 1) denote a more favorable adsorption process (Naiya et al. 2009). The values of the constant parameters were calculated from the slope and intercept of the linear plot of $\log q_{\mathrm{e}}$ versus $\log C_{\mathrm{e}}$. The constant parameters $K_{\mathrm{f}}$ and $\mathrm{n}$ calculated from the present study are recorded in (Table 2). The values of $n$ for both adsorbents are between 1 and 10 an indication of beneficial adsorption. The correlation coefficient $\left(R^{2}\right)$ obtained from the linear plot of this isotherm model (Fig. 9c, d) for the study is 0.924 and 0.989 for $\mathrm{RH}-\mathrm{AC}$ and $\mathrm{PP}-\mathrm{AC}$, respectively. The correlation coefficients results clearly indicate that the adsorption of chromium ions in aqueous solution on $\mathrm{PP}-\mathrm{AC}$ fitted best on Freundlich isotherm model compared to the Langmuir model. The successful fitting of experimental data on the Freundlich model suggests the physical adsorptions as well as the heterogeneous distribution of the active sites on the surface of the PP-AC surface (Dula et al.
2014). RH-AC demonstrated a good fit in the Langmuir model, unlike the Freundlich isotherm model.

\section{Temkin isotherm}

Temkin adsorption isotherm recognized the effects of some indirect adsorbent adsorbate interaction on adsorption isotherms and proposed that the heat of adsorption of all the molecules in the layer would linearly reduce with coverage due to these interactions (Benzaoui et al. 2018). The linear relationship form of the Temkin isotherm model is represented by the following equation:

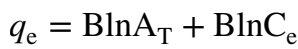

where $B=\mathrm{RT} / b_{\mathrm{T}}, T$ is the absolute temperature in $\mathrm{K} ; R$ is the universal gas constant. $(\mathrm{J} / \mathrm{Mol}) b_{\mathrm{T}}$ is related to the heat of adsorption and $A_{\mathrm{T}}$ is the equilibrium binding constant that corresponds to the maximum binding energy. This model assumes that adsorption happens due to equal distribution of binding energy (Gottipati 2012). The constant parameters of this isotherm are calculated from the intercept and slope of the linear plot of $q_{\mathrm{e}}$ versus $\ln \mathrm{Ce}$. The value parameters calculated are displayed in (Table 2 ). The positive values of Temkin's model adsorption energy $\left(b_{\mathrm{T}}\right)$ in the present study is an indication that the adsorption process was endothermic in nature (Singh et al. 2014). The low regression coefficient $R^{2}$ achieved 0.973 and 0.923 for RH-AC and PP-AC, respectively, also confirms that the adsorption data does not favor this isotherm model (Fig. 10a, b).

(b)
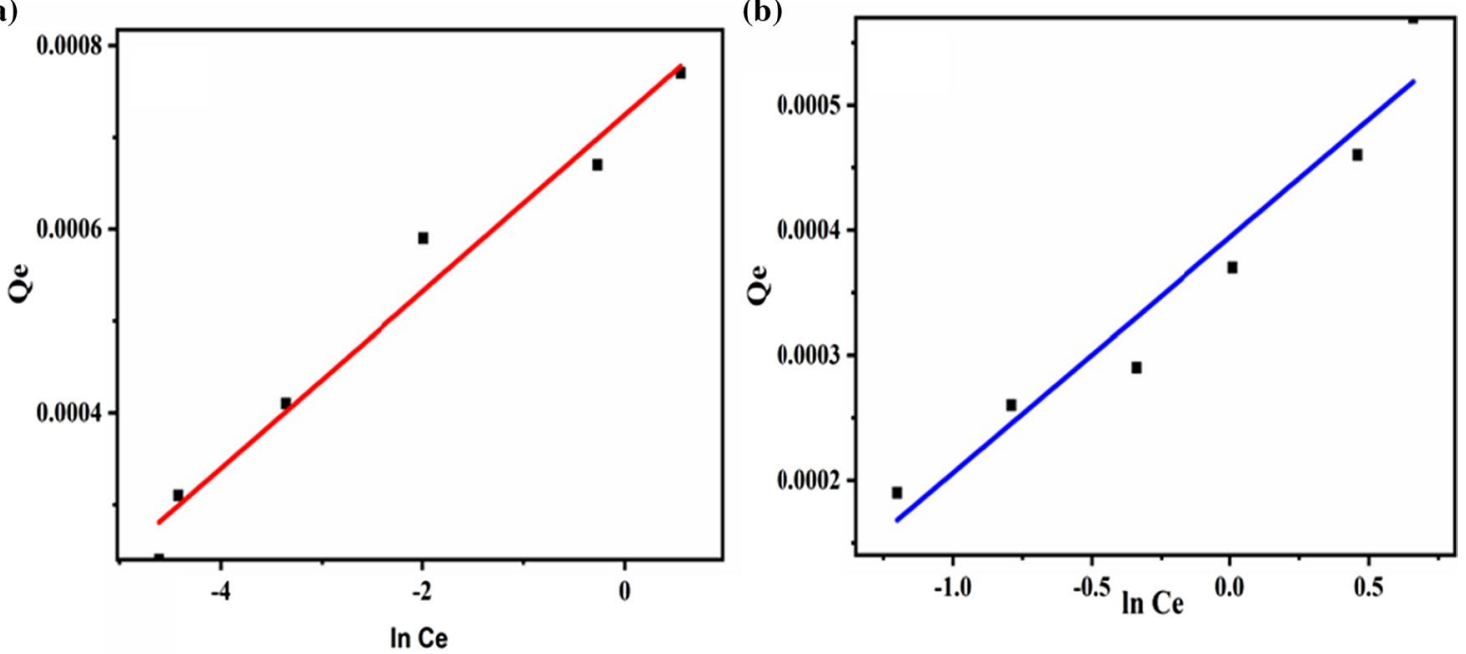

Fig. 10 Temkin plot for Cr adsorption on $\mathrm{RH}-\mathrm{AC}(\mathbf{a})$; and PP-AC (b) 


\section{Adsorption kinetic study}

Different kinetic models are proposed to examine the mechanism of solute adsorption by the adsorbent and chemical reaction (Kumar et al. 2010). The kinetics studies demonstrate the solute uptake rate and evidently, controls the residence time of adsorbate uptake at the solid-liquid interface (Chakravarty et al. 2010). The study applied two commonly used kinetic models to describe the adsorption of chromium ions by activated carbons understudy.

\section{The pseudo-first-order kinetic model}

The kinetic model of Lagergren, also termed as pseudo-firstorder kinetic expression, is the most extensively used model. The linear form of the Lagergren kinetic model is denoted by the following equation:

$\log \left(q_{\mathrm{e}}-q_{\mathrm{t}}\right)=\log q_{\mathrm{e}}-K_{\mathrm{t}}$

where $q_{\mathrm{e}}$ and $q_{\mathrm{t}}$ represents the quantity of adsorbate adsorbed $(\mathrm{mg} / \mathrm{g})$ at equilibrium and at time $t$, respectively, $K_{\mathrm{t}}\left(\mathrm{min}^{-1}\right)$ is the Lagergren rate constant. The pseudo-first-order plot of a kinetic model at an initial concentration of $3.249 \mathrm{mg} / \mathrm{L}$ at room temperature is displayed in (Fig. 11a, b). The values $k_{1}$ and $q_{\mathrm{e}}$ shown in (Table 2) were calculated from the slopes and intercepts of the linear plot of $\log \left(q_{\mathrm{e}}-q_{\mathrm{t}}\right)$ versus time $\mathrm{t}$, of pseudo-first-order model. The correlation coefficients $\left(R^{2}\right)$ obtained (shown in Table 2) for both adsorbents are a little higher, but less compared with those gotten from pseudosecond-order model. The results suggest that the adsorption data for chromium ions by RH-AC and PP-AC could not favor the first-order kinetic model.

\section{The pseudo-second-order kinetic model}

The adsorption kinetics may also be expressed by pseudosecond-order model. This kinetic model is also based on the assumption that the adsorption that the rate is controlled by a chemical adsorption mechanism plus sharing or transferring
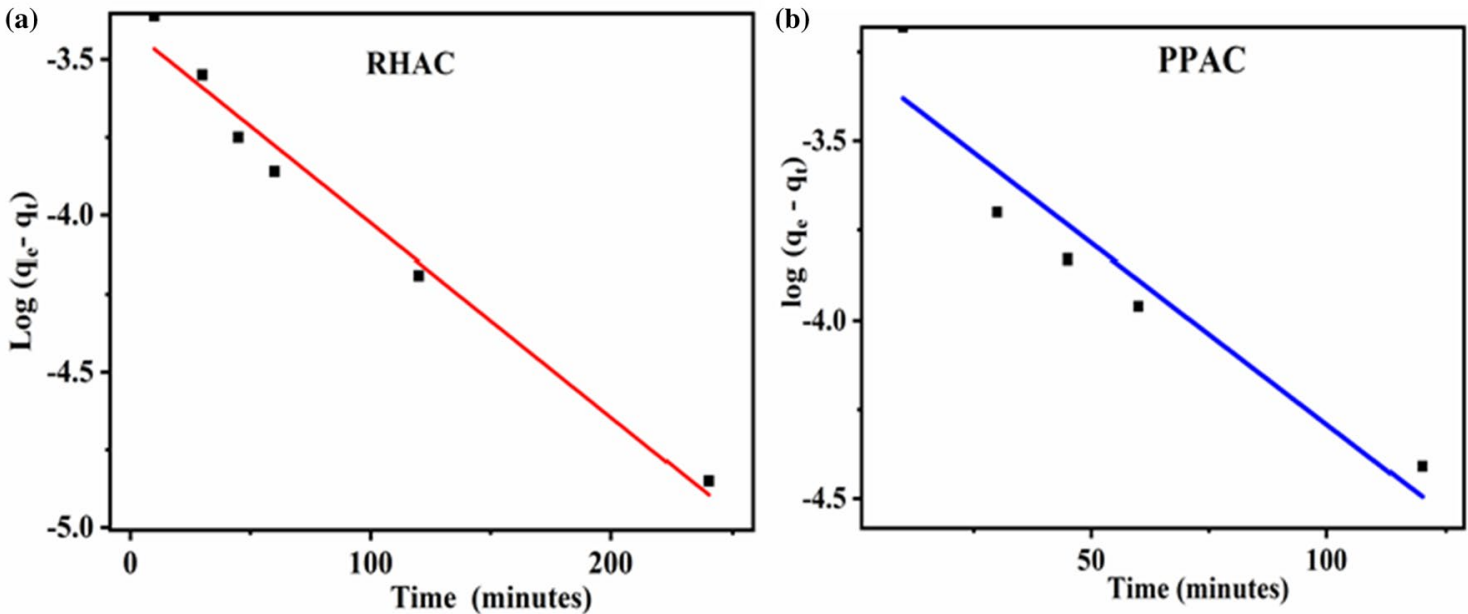

(c)

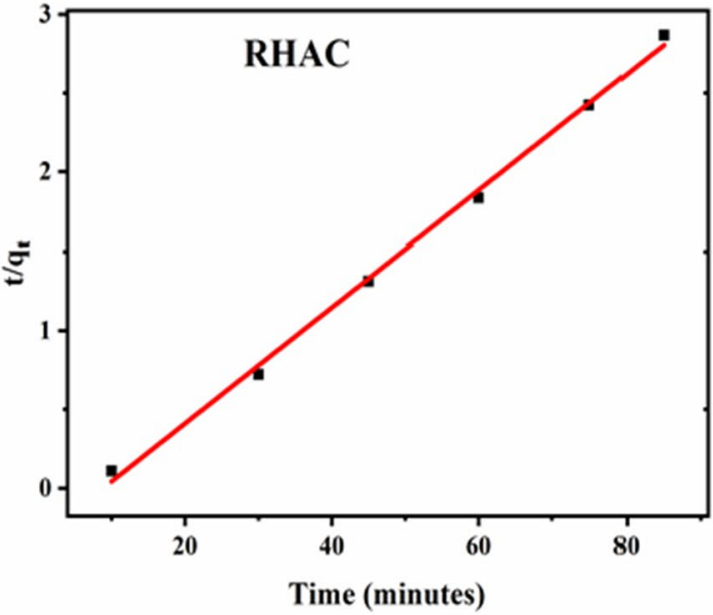

(d)

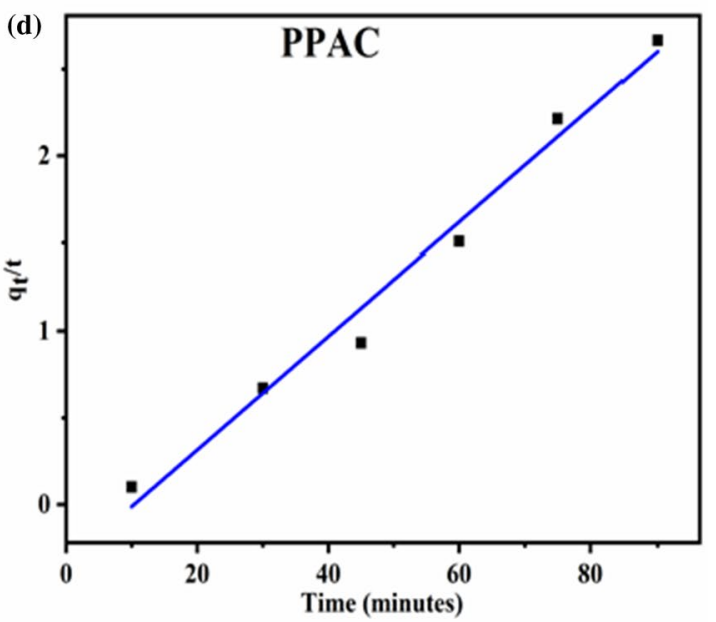

Fig. 11 Plot of pseudo-first-order (a, b) and pseudo-second-order (c, d) 
of electron between the adsorbent and the adsorbate (Khandanlou 2015). The linearized form of the pseudo-secondorder kinetic model is given by the following equation (Kim et al. 2018).

$\frac{t}{q_{\mathrm{t}}}=\frac{1}{K_{2} q_{\mathrm{e}}^{2}}+\frac{t}{q_{\mathrm{e}}}$

where $q_{\mathrm{e}}$ and $q_{\mathrm{t}}$ represent the quantity of the adsorbate adsorbed $(\mathrm{mg} / \mathrm{g})$ at equilibrium and at time $t$, respectively. The constant of the pseudo-second-order kinetic adsorption model is denoted by $K_{2}$ in $(\mathrm{g} / \mathrm{mg} / \mathrm{min})$. The straight-line plots (Fig. 11c, d) of $t / q_{t}$ against $t$, provides an understanding to the above equation to chromium ions adsorption on prepared adsorbents. The intercepts and slopes of the above plots give the constant parameters. The correlation coefficient $\left(R^{2}\right)$, together with the uptake capacity $\left(q_{\mathrm{e}}\right)$ and the second-order rate constant $\left(K_{1}\right)$ calculated at room temperature are shown in (Table 2). The regression coefficients attained are higher for adsorbents in comparison with that of pseudo-first-order. Therefore, the adsorption kinetics data of chromium ions by synthesized activated carbons could be described better with this kinetic model. Similar pattern of results is also reported by previous investigators on adsorption of $\mathrm{Cr}$ ions from aqueous solution using different adsorbents (Khandanlou et al. 2015; Singh et al. 2014).

\section{Desorption and reusability studies}

Economical and feasibility of the adsorption process is much dependent on adsorbent regeneration. If the material can be renewed and reused as an adsorbent after the first phase of the adsorption process, then, the economic improvement of the adsorption process will be attained (Ahmad et al. 2012). The regeneration studies of the prepared activated carbon were assessed and the results suggest that the adsorbents understudy could be used for three times before losing the affinity for chromium ions uptake. As shown in (Fig. 12), a slight difference especially for the first two cycles was realized. The recorded results for three cycles of the regeneration studies ranged as follows: $8.909-5.486 \mathrm{mg} / \mathrm{L}$ and $8.004-5.713 \mathrm{mg} / \mathrm{L}$ for $\mathrm{RH}-\mathrm{AC}$ and $\mathrm{PP}-\mathrm{AC}$, respectively. The results also indicate that the elution agent was suitable to desorb chromium ions from the adsorbents understudy.

\section{Conclusion}

The present study has shown the effectiveness of activated carbons derived from the agro-wastes through chemical activation for the removal of chromium ions from tannery effluents. The efficacy of RH-AC and PP-AC was

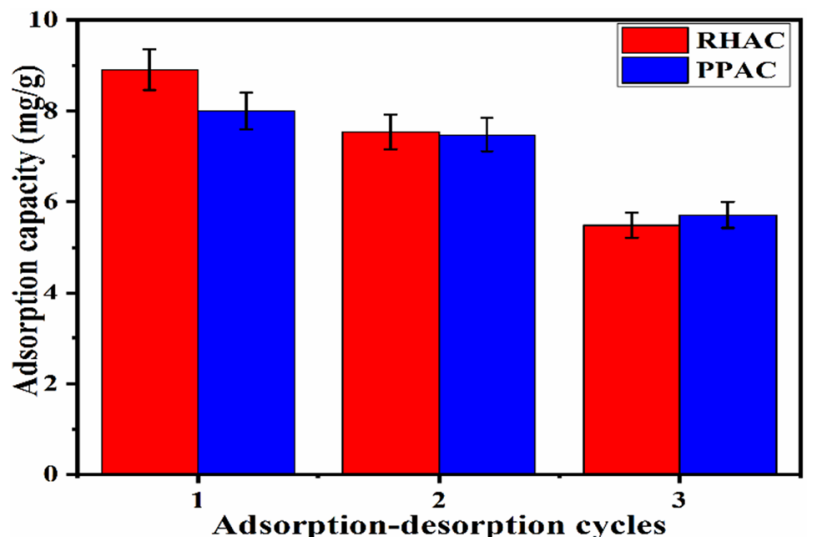

Fig. 12 Adsorption-desorption cycles of chromium ions by $\mathrm{RH}-\mathrm{AC}$ and $\mathrm{PP}-\mathrm{AC}$

evaluated through batch adsorption study with a variation on solution $\mathrm{pH}$, initial concentration, adsorbent dosage, contact time and agitation speed. The equilibrium data for $\mathrm{Cr}(\mathrm{IV})$ ions adsorption onto $\mathrm{RH}-\mathrm{AC}$ and $\mathrm{PP}-\mathrm{AC}$ satisfactorily fitted well in the Langmuir and the Freundlich isotherms, respectively. The kinetics results have shown that the adsorption of $\mathrm{Cr}(\mathrm{IV})$ ions fitted successfully in pseudo-second-order kinetic model with a regression coefficient $(>0.9$ ) for both adsorbents. The results obtained from regeneration studies confirm that the adsorbents prepared could be regenerated and reused before losing adsorbing affinity for chromium ions. Finally, the synthesized activated carbons could be possible substitutes for the exorbitant commercial activated carbons for the removal of chemical pollutants from both water and wastewaters as they have demonstrated effective in the uptake of chromium ions from effluents originating from the tannery industry. The fact that the precursors used in the preparation of activated carbons (RH-AC and $\mathrm{PP}-\mathrm{AC}$ ) are available in abundance at zero cost, offer a great opportunity to reduce water pollution due to chemical contaminants and reduce environmental pollution associated with agricultural wastes disposal.

Acknowledgements This research was supported by The World Academic of Sciences (TWAS) Research Grant Agreement (RGA): No. 17-490 RG/CHE/AF/AC_G-FR3240297725. The authors acknowledge the Department of Chemistry, Chancellor College, University of Malawi for the use of their laboratory and to the University of the Witwatersrand, South Africa, for making use of their instruments. The authors are also thankful to the Management of Liwonde Leather Tannery, for granting them permission to use the factory's wastewater to conduct this research for academic purpose.

Funding The World Academic of Science (TWAS) Research Grant Agreement (RGA): No. 17-490 RG/CHE/AF/AC_G-FR3240297725 


\section{Declarations}

Conflict of interest The authors confirm that this manuscript has no conflicts of interest.

Open Access This article is licensed under a Creative Commons Attribution 4.0 International License, which permits use, sharing, adaptation, distribution and reproduction in any medium or format, as long as you give appropriate credit to the original author(s) and the source, provide a link to the Creative Commons licence, and indicate if changes were made. The images or other third party material in this article are included in the article's Creative Commons licence, unless indicated otherwise in a credit line to the material. If material is not included in the article's Creative Commons licence and your intended use is not permitted by statutory regulation or exceeds the permitted use, you will need to obtain permission directly from the copyright holder. To view a copy of this licence, visit http://creativecommons.org/licenses/by/4.0/.

\section{References}

Ahmad R, Kumar R, Haseeb S (2012) Adsorption of $\mathrm{Cu}^{2+}$ from aqueous solution onto iron oxide coated eggshell powder: evaluation of equilibrium, isotherms, kinetics, and regeneration capacity. Arab J Chem 5(3):353-359

Almohammadi S, Mirzaei M (2016) Removal of copper(II) from aqueous solutions by adsorption onto granular activated carbon in the presence of competitor ions. Adv Environ Technol 2:85-94

Anirudhan TS, Sreekumari SS (2011) Adsorptive removal of heavy metal ions from industrial effluents using activated carbon derived from waste coconut buttons. J Environ Sci 23(12):1989-1998

Awwad NS, Gad HMH, Ahmad MI, Aly HF (2010) Sorption of lanthanum and erbium from aqueous solution by activated carbon prepared from rice husk. Colloid Surf Biointerfaces 1(81):593-599

Barot NS, Bagla HK (2012) Eco-friendly wastewater treatment by cow dung powder Adsorption studies of $\mathrm{Cr}(\mathrm{III}), \mathrm{Cr}(\mathrm{VI})$ and $\mathrm{Cd}(\mathrm{II})$ using tracer technique. Desalinat Water Treat 38(1-3):104-113

Benzaoui T, Selatnia A, Djabali D (2018) Adsorption of copper(II) ions from aqueous solution using bottom ash of expired drugs incineration. Adsorpt Sci Technol 36:114-129

Berihun D (2016) Removal of chromium from industrial wastewater by adsorption using agricultural wastes. J Mater Sci Eng 6(2):6-11

Bishnoi NR, Bajaj M, Sharma N, Gupta A (2004) Adsorption of Cr(VI) on activated rice husk carbon and activated alumina. Bioresour Technol 91:305-307

Chakravarty P, SenSarma N, Sarma HP (2010) Biosorption of cadmium(II) from aqueous solution using heartwood powder of (Areca catechu). Chem Eng J 162:949-955

Chen Y, Sun S, Gao J, Qian L (2018) Reduction and removal of chromium(VI) in water. Multidisiplinary Digit Publ Inst Mater. https://doi.org/10.3390/mal1020269

Demiral I, Tumsek F, Karabacako B, Demiral H (2008) Adsorption of chromium(VI) from aqueous solution by activated carbon derived from olive bagasse and applicability of different adsorption models. Chem Eng J 144:188-196

Devi MM, Manonmani S (2015) Removal of hexavalent chromium ions from aqueous solution by adsorption using activated carbon prepared from Cucumis melo peel activated carbon. Orient J Chem 31(1):531-539

Dula T, Siraj K, Kitte SA (2014) Adsorption of hexavalent chromium from aqueous solution using chemically activated carbon prepared from locally available waste of bamboo (Oxytenanthera abyssinica). Environ Chem. https://doi.org/10.1155/2014/438245
Fabbricino M, Gallo R (2010) Chromium removal from tannery wastewater using ground shrimp shells. Desalinat Water Treat 23(1-3):194-198

Ghaedi M, Nasab AG, Khodadoust S, Sahraei R, Daneshfar A (2014) Characterization of zinc oxide nanorods loaded on activated carbon as cheap and efficient adsorbent for removal of methylene blue. J Ind Eng Chem. https://doi.org/10.1016/j.jiec.2014.05.006

Girgis BS, Temerk YM, Gadelrab MM, Abdullah ID (2007) X-ray diffraction patterns of activated carbons prepared under various conditions. Carbon Sci 8(2):95-100

Gottipati R (2012) Preparation and characterization of microporous activated carbon from biomass and its application in the removal of chromium(VI) from aqueous phase. (Phd Thesis) Department of Chemical Engineering, National Institute of Technology, Rourkela, India

Gueye M, Richardson YFT, Kafack BJ (2014) High efficiency activated carbons from african biomass residues for the removal of chromium(VI) from wastewater. Biochem Pharmacol 2(1):273-281

Guo Z, Xu L, Liu C, Sun F, Kang Y, Liang S (2015) Comparison of physicochemical properties of activated carbons derived from biomass wastes by $\mathrm{H}_{4} \mathrm{P}_{2} \mathrm{O}_{7}$ activation: Adsorption of trimethoprim. Desalinat Water Treat 57(46):21957-21967

Hameed BH, Mahmoud DK, Ahmad AL (2008) Equilibrium modeling and kinetic studies on the adsorption of basic dye by a low-cost adsorbent: coconut (Cocos nucifera) bunch waste. J Hazard Mater 158:65-72

Hashemian S, Salari K, Salehifar H, Yazdi ZA (2015) Removal of azo dyes:violet $\mathrm{b}$ and violet $5 \mathrm{R}$ from aqueous solution using new activated carbon developed from orange peel. J Chem. https:// doi.org/10.1155/2013/283274

Islam S, Ang BC, Gharehkhani S, Binti A, Afifi M (2016) Adsorption capability of activated carbon synthesized from coconut shell. Koreen Carbon Soc 20:1-9

Kaushal A, Singh S (2017) Adsorption phenomenon and its application in removal of lead from wastewater: a review. Int J Hydrol 1(2):38-47

Khandanlou R, Ahmad MB, Reza H, Masoumi F (2015) Rapid adsorption of copper(II) and lead(II) by rice straw/ $/ \mathrm{Fe}_{3} \mathrm{O}_{4}$ nanocomposite: optimization, equilibrium isotherms, and adsorption kinetics study. PLoS ONE. https://doi.org/10.1371/journ al.pone. 0120264

Kilic M, Apaydin-Varol E, Putun AE (2014) Thermodynamic and kinetic studies for the adsorption of cadmium(II) ions onto activated carbon prepared from (Euphorbia rigida) by chemical activation. Energy sour part A: Recovery Utilization Environ Effects 36(16): 1727-1737

Kim T, Kim T, Choe W, Kim M, Jung Y, Zoh K (2018) Removal of heavy metals in electroplating wastewater by powdered activated carbon (PAC) and sodium diethyldithiocarbamate-modified PAC. Environ Eng Resour 23(3):301-308

Kumar PS, Ramalingam S, Senthamarai C, Niranjanaa M, Vijayalakshmi P, Sivanesan S (2010) Adsorption of dye from aqueous solution by cashew nut shell: studies on equilibrium isotherm, kinetics and thermodynamics of interactions. Desalination Water Treat 261:52-60

Kumar R, Ehsan M, Barakat MA (2014) Synthesis and characterization of carbon/AlOOH composite for adsorption of chromium(VI) from synthetic wastewater. J Ind Eng Chem 20(6):4202-4206. https://doi.org/10.1016/j.jiec.2014.01.021

Lataye D, Malwade D, Kurwadkar V, Mhaisalkar S, Ramirez D (2016) Adsorption of hexavalent chromium onto activated carbon derived from Leucaena leucocephala waste sawdust: kinetics, equilibrium and thermodynamics. Int J Environ Sci Technol 13(9):2107-2116 
Li Y, Zhang X, Yang R, Li G, Hu C (2015) The role of $\mathrm{H}_{3} \mathrm{PO}_{4}$ in the preparation of activated carbon from $\mathrm{NaOH}$-treated rice husk residue. Royal Soc Chem 5:32626-32636

Madala S, Kumar S, Vudagandla S, Boddu V, Abburi K (2013) Equilibrium, kinetics and thermodynamics of cadmium(II) biosorption onto composite chitosan biosorbent. Arabian J Chem 10:S1883-S1893

Mandal AB (2013) Adsorption isotherms, kinetics and mechanism for the adsorption of cationic and anionic dyes onto carbonaceous particles prepared from Juglans regia shell biomass. Int J Environ Sci Technol 10(2):231-242. https://doi.org/10.1007/ s13762-012-0112-0

Mohanty S, Bal B, Das AP (2014) Adsorption of hexavalent chromium onto activated carbon. Austin J Biotechnol Bioeng 1:1-5

Mullick A, Moulik S, Bhattacharjee S (2017) Removal of hexavalent chromium from aqueous solutions by low-cost rice husk-based activated carbon: Kinetic and Thermodynamic studies. Indian Chem Eng. https://doi.org/10.1080/00194506.2017.1288173

Murugesan A, Vidhyadevi T, Kirupha D, Ravikumar L, Sivanesan S (2012) Removal of chromium(VI) from aqueous solution using chemically modified corncorb-activated carbon: Equilibrium and kinetic studies. Environ Prog Sustain Energy 32(3):673-680. https://doi.org/10.1002/ep.11684

Nahid MG, Mohamed HI, Muftah HE, Awad EA (2020) Chromium removal from tannery wastewater by electrocoagulation: optimization and sludge characterization. Water 12:1374. https://doi.org/ $10.3390 /$ w12051374

Naiya T, Bhattacharya A, Mandal S, Kumar S (2009) The sorption of lead(II) ions on rice husk ash. J Hazard Mater 163:1254-1264

Onindo CO, Muthakia GK (2012) Kinetic and equilibrium study for the sorption of $\mathrm{Pb}$ (II) ions from aqueous phase by water hyacinth (Eichhornia crassipes). Chem Soc Ethiop 26:181-193

Qin C, Chen Y, Gao J (2014) Manufacture and characterization of activated carbon from marigold straw (Tagetes erecta) by $\mathrm{H}_{3} \mathrm{PO}_{4}$ chemical activation. Mater Lett 135:123-126

Rahman MW, Ali MY, Saha I, AlRaihan M (2017) Date palm fiber as a potential low-cost adsorbent to uptake chromium(VI) from industrial wastewater. Desalination Water Treat 88:169-178

Rai MK (2016) Removal of hexavalent chromium Cr(VI) using activated carbon prepared from mango kernel activated with $\mathrm{H}_{3} \mathrm{PO}_{4}$. Resour Technol 2:63-70

Santhosh P, Dhandapani C (2013) Adsorption studies on the removal of chromium(VI) from wastewater using activated carbon derived from water hyacinth. Nature Environ Pollut Technol 12(4):563-568

Siboni MS, Samarghandi MR, Azizian S, Kim WG, Lee SM (2011) The Removal of hexavalent chromium from aqueous solutions using modified holly sawdust: Equilibrium and kinetics studies. Environ Eng Res 16(2):55-60

Singh D, Kumar R, Kumar B, Shankar V, Krishna V (2014) Citric acid coated magnetic nanoparticles: synthesis, characterization and application in removal of $\mathrm{Cd}(\mathrm{II})$ ions from aqueous solution. Water Process Eng 4:233-241

Sugashini S, Mohamed K, Sheriffa M (2015) Preparation of activated carbon from carbonized rice husk by ozone activation for $\mathrm{Cr}(\mathrm{VI})$ removal. New Carbon Mater 30(3):252-261

Venkata DKV, Min K (2015) Activated carbon produced from pigeon peas hulls waste as a low-cost agro-waste adsorbent for $\mathrm{Cu}$ (II) and Cd(II) removal. Desalinat Water Treat. https://doi.org/10.1080/ 19443994.2015.1013509

Vunain E, Biswick T (2018) Adsorptive removal of methylene blue from aqueous solution on activated carbon prepared from Malawian baobab fruit shell wastes: equilibrium, kinetics and thermodynamic studies. Sep Sci Technol. https://doi.org/10.1080/ 01496395.2018.1504794

Vunain E, Kenneth D, Biswick T (2017) Synthesis and characterization of low-cost activated carbon prepared from Malawian baobab fruit shells by $\mathrm{H}_{3} \mathrm{PO}_{4}$ activation for removal of $\mathrm{Cu}$ (II) ions: equilibrium and kinetics studies. Appl Water Sci 7(8):4301-4319

Yang J, Yu M, Chen W (2014) Adsorption of hexavalent chromium from aqueous solution by activated carbon prepared from longan seed:Kinetics, equilibrium and thermodynamics. J Ind Eng Chem 21:414-422

Yavuz R, Orbak I, Nilgun Karatepe N (2006) Factors affecting the adsorption of chromium(VI) on activated carbon. J Environ Sci Health Part A 41:1967-1980

Yusuff AS (2019) Adsorption of hexavalent chromium from aqueous solution by Leucaena leucocephala seed pod activated carbon:Equilibrium, kinetic and thermodynamic studies. Arab J Basic Appl Sci. https://doi.org/10.1080/25765299.2019.1567656

Publisher's Note Springer Nature remains neutral with regard to jurisdictional claims in published maps and institutional affiliations. 